\title{
STUDY OF CERTAIN EPIDEMIOLOGICAL FACTORS AFFECTING OUTCOME OF ACUTE RESPIRATORY INFECTIONS IN CHILDREN ADMITTED IN A TERTIARY CARE HOSPITAL OF WESTERN MAHARASHTRA
}

\author{
Jayashree D. Naik' ${ }^{1}$, Sandeep P. Suryawanshi², Mathurkar M. P3, Swapnil R. Jain ${ }^{4}$, Sheetu M. K. Jailkhani5, Madhav S. Thakur6, \\ Sandesh V. Kamble ${ }^{7}$, Jitendra R. Dolare ${ }^{8}$ \\ 1 Professor and HOD, Department of Community Medicine, Government Medical College, Miraj, Maharashtra. \\ ${ }_{2}^{2}$ Medical Officer, District Nucleus Team, Assistant Director Health Services, Leprosy, NAshik, Maharashtra. \\ 3 Junior Resident, Department of Community Medicine, Government Medical College, Miraj, Maharashtra. \\ ${ }^{4}$ Assistant Professor, Department of Community Medicine, Government Medical College, Miraj, Maharashtra. \\ ${ }_{5}^{5}$ Medical Officer at Assistant Director Health Services (Leprosy), Kolhapur, Maharashtra. \\ ${ }^{6}$ Medical Officer at Dist.TB Centre, Sangli, Maharashtra. \\ 7Junior Resident, Department of Community Medicine, Government Medical College, Miraj, Maharashtra. \\ ${ }^{8}$ State Epidemic Medical Officer, Joint Director Health Services, Pune.
}

ABSTRACT: BACKGROUND: The incidence of acute respiratory infections (ARI) is high among under-fi ve children, especially in developing countries. However, the data on ARI from urban areas in India are scarce.

AIM: To assess various socio-demographic and environmental factors of ARI cases admitted in tertiary care hospital and to determine their association with outcome of disease.

STUDY DESIGN AND SETTING: A Cross-sectional descriptive study conducted in a tertiary care hospital in Western Maharashtra, targeting all ARI cases admitted over a period of $1 \mathrm{yr}$. in the Pediatric ward at Govt. Medical College \& Hospital, Miraj, from 1 January to 31 December 2011.

METHODS AND MATERIALS: A pre- tested structured questionnaire with details regarding socio demographic characteristics and Environmental factors influencing outcome of ARI cases was used to collect the information from person accompanying ARI child preferably mother.

STATISTICAL ANALYSIS: Statistical software SPSS 16 for proportions, chi square test and odds ratio.

RESULTS: Out of all (352) cases of ARI, 93.75\% (330) were cured and 6.25\% (22) were died. In this study majority of cases were less than one year, mostly among boys from joint family, urban area, Hindu religion. Socioeconomic status and family history of smoking, were statistically significant while overcrowding, seasonal variation and Type of fuel for cooking were not significantly associated with outcome of ARI.

CONCLUSION: Efforts should be made to improve the socio-economic and environmental status of the parents by the administration. Improving them can reduce the incidence of the Acute respiratory infection among the under five children and better outcome of disease.

KEYWORDS: ARI, Socio Demographic Variable, Overcrowding, Indoor Air Pollution, Pneumonia.

HOW TO CITE THIS ARTICLE: Jayashree D. Naik, Sandeep P. Suryawanshi, Mathurkar M. P, Swapnil R. Jain, Sheetu M. K. Jailkhani, Madhav S. Thakur, Sandesh V. Kamble, Jitendra R. Dolare. "Study of Certain Epidemiological Factors Affecting Outcome of Acute Respiratory Infections in Children Admitted in a Tertiary Care Hospital Of Western Maharashtra". Journal of Evolution of Medical and Dental Sciences 2015; Vol. 4, Issue 89, November 05; Page: 15418-15421, DOI: 10.14260/jemds/2015/2199.

INTRODUCTION: Childhood Acute Respiratory Infection (ARI) is the largest cause of morbidity among under-five children across the world. ARI compromises inflammation of respiratory tract anywhere from nose to alveoli, with a wide range of combination of symptoms and signs. ${ }^{1}$ ARI continues to be the leading cause of acute illnesses worldwide and remains the most important cause of infant and young children mortality, accounting for about two millions deaths each year and ranking first among causes of dispabillityadjusted life years (DALYs) lost in developing countries.

Financial or Other, Competing Interest: None.

Submission 13-10-2015, Peer Review 14-10-2015,

Acceptance 15-10-2015, Published 04-11-2015.

Corresponding Author:

Dr. Swapnil. R. Jain,

Department of Community Medicine,

Government Medical College,

Miraj, 416410, Dist-Sangli, Maharashtra.

E-mail: sjvicky85@gmail.com

DOI:10.14260/jemds/2015/2199.
In developing countries $30 \%$ of all patients' consultation and $25 \%$ of all pediatric admission are of ARI. Most infections are limited to the upper respiratory tract and $5 \%$ involve the lower respiratory tract. Incidence of ARI is almost the same all over the world. 5-7 episodes per child per year in urban areas and 3-5 episodes in rural area. ${ }^{2}$ Mortality due to ARI is high in developing countries which may reach 1000 or more 100000 live births compared to $30-40 \%$ per 100000 live births in industrialized nations. In all countries ARI is the leading cause of hospitalization and death. Therefore ARI represent a large challenge in field of communicable diseases. ${ }^{2}$ In spite of increasing public health importance, management and control of ARI remains a neglected entity in most of the National Maternal and Child Health (MCH) activities. ${ }^{3}$

In view of above context, the present study was carried out to assess various socio-demographic and environmental factors of ARI cases admitted in tertiary care hospital and to determine their association with outcome of disease. 
MATERIALS AND METHODS: A descriptive cross sectional, hospital based study conducted in Government Medical College and Hospital in Western Maharashtra over period of one calendar year from January 2011 to December 2011.It was a part of project conducted under department of community medicine GMC Miraj Maharashtra. Prior permission from the institutional ethical commitee was obtained and verbal informed consent was taken from person accompanying the ARI child; preferably the mother were interviewed. Care was taken to avoid any duplication.

Acute respiratory tract infections were classified depending on whether they affect the upper or lower respiratory tract. The upper respiratory tract consists of the airways from the nostrils, to the vocal cords in the larynx, including the paranasal sinuses and middle ear.

They include rhinitis, sinusitis, ear infections, acute pharyngitis or tonsillopharyngitis, epiglottitis, and laryngitis. Ear infections and pharyngitis cause the more severe complications. ${ }^{4}$ the lower respiratory tract covers the continuation of the airways from the trachea and bronchi to the bronchiole and alveoli. The most common lower respiratory tract infections are pneumonia, bronchitis and bronchiolitis. All cases of ARI admitted in Paediatrics ward at Govt. Medical College and Hospital were examined and interview of the person accompanying the child; preferably the mother, was taken on the same day.

The information regarding the Socio-demographic factors \& Environmental factors was recorded on predesigned, pretested, questionnaire. The association between outcome of ARI cases with socio-demographic characteristics \& Environmental variables were studied. Statistical analysis was done by percentages, proportions, univariate analysis and Chi-square test.

RESULTS: Out of total 363 cases admitted in the hospital, 352 could be covered/interviewed and examined. The remaining 11 could not be included in the study due to various reasons viz. not willing to participate/noncooperation of the caretakers/ parents accompanying the child for interview and examination, discharged against medical advice/ discharged on request etc.

Table 1 shows that out of 352 cases, 330(93.75\%) cases were cured and remaining $22(6.25 \%)$ cases died due to ARI. None of the socio-demographic factors studied like age, gender, residence, religion, type of family, socioeconomic status and education of parents were significantly associated with outcome of ARI. Out of 187 cases in the age group <1 year, 173(92.51\%) cases cured and while $14(7.49 \%)$ died due to ARI.

Out of 115 cases in the age group 1-5 year, $109(94.78 \%)$ were cured and $6(5.22 \%)$ died due to ARI. Similarly in the age $>5$ years, out of 50 cases, $48(96.00 \%)$ were cured and only $2(4.00 \%)$ died due to ARI. Among 352 cases, majority were males i.e 214(60.8\%) while only $138(39.2 \%)$ cases were females. Male female ratio was 1.5:1.With regard to residence majority i.e $240(68.18 \%)$ cases were from urban area. Proportion of Hindus was more $240(68.18 \%)$ as compared to other religions.Maximum i.e. $177(50.28 \%)$ cases of ARI had come from joint family followed by nuclear family $134(38.07 \%)$ and three generation family $41(11.65 \%)$.

Out of 352 cases, 230 (65.34\%) cases belonged to lower class, $121(34.38 \%)$ cases belonged to Middle class and only $1(0.28 \%)$ case belonged to Upper class.
Observed deaths were $19(86.36 \%)$ in lower socioeconomic class, $3(13.64 \%)$ in middle socioeconomic class and no death was observed from upper socioeconomic class. Cases from lower socioeconomic class showed risk of death 3.57 times that of cases from middle and upper socioeconomic class.

[Table 3] $110(31.25 \%)$ mothers were illiterate. $80(22.73 \%)$ mothers were educated up to primary school while $61(17.33 \%)$ mothers were educated up to middle school. $56(15.91 \%)$ mothers were educated up to secondary school. $33(9.37 \%)$ mothers were studied up to higher secondary school and remaining $12(3.41 \%)$ mothers were graduate/postgraduate. Out of total 22 deaths, $10(45.45 \%)$ deaths were in children of illiterate mothers. $6(27.27 \%)$ deaths were in those mothers were educated up to primary school. 3(13.64\%) deaths were in children of the middle school educated mothers. $2(9.09 \%)$ deaths were in children of mothers educated up to secondary school. $1(4.55 \%)$ death was in child of the higher secondary educated and no death was found in children of graduate/postgraduate mothers. [Table 1]

Among environmental factors studied, Family history of smoking was significantly associated while type of fuel used, overcrowding and seasonal variation were not in significant association with outcome of ARI. It is seen from above table that out of 352 cases, maximum (57.10\%) had Family history of smoking. Table 3 shows that cases with family history of smoking had risk of death 2.70 times then without family history of smoking. 320 (90.91\%) cases were from the families using cooking fuel other than LPG. Overcrowding was present in 294(83.52\%) cases. Majority of cases, 153(43.46\%) were admitted in winter season while only $87(24.72 \%)$ cases were admitted in summer season [Table 2]

DISCUSSION: In the present study maximum i.e, 187(53.13\%) cases of ARI were in the age group of $<1$ year. These observation of present study were comparable with the following studies Bharti B et al..$^{5}$ in their study also revealed that majority of children affected were infants and toddlers (77.4\%); infants up to 12 months alone were $46.1 \%$ and only $9.06 \%$ of cases were above the age of 5 year.

Probable reasons for highest incidence in the first and gradual decline later are smaller airways more compliant chest wall and poor hypoxic drive, immunological immaturity, lack in cellular as well as humoral immunity in infancy. Baqui AH et al. ${ }^{6}$ in their study also observed that the rate of hospitalization was higher in males than in females which corroborates with current study. This could be due to higher rates of care seeking behaviour for male children than for female children, giving strong preference for sons.

Similar to this study Yousif TK et $a .^{2}$ also found most of cases were from urban area. More no of cases in urban area could be due to regional factors and also location of hospital in urban area. In general population and as per census proportion of Hindus was more as compared to other religions and same was observed in this study. The joint family is a kind of family grouping which is common in India. As the proportions of Hindus were more in present study, joint family pattern was observed.

Similarly Savitha MR et $\mathrm{al}^{7}$ also revealed similar findings that the majority of ARI cases were coming from lower socioeconomic class. More no of cases and higher maortality in lower socio-economic class could be due to negligence, lack of knowledge about disease, affordability of treatement, preference for low cost indigenous remedies. As per census, female and male literacy rate observed. 
Illiterate mothers were $110(31.25 \%)$, while $242(68.75 \%)$ mothers were literate. These findings were consistent with study by Broor S et al (2001). ${ }^{8}$ and Yousif TK et $\operatorname{al}(2006) .^{2}$

Observed data in present study shows that mortality rate was inversely proportional to the literacy of the mother as literacy increases mortality decreases. But it was not statistically significant. In current study children of illiterate fathers were $82(23.30 \%)$ while remaining $270(76.7 \%)$ were literate similar to study conducted by Sahu sk et al(2002). ${ }^{9}$ where $80.7 \%$ were literate.

Observed deaths were more in cases due to family history of smoking as compared to without family h/o smoking. This difference was statistically significant consistent with previous study by Mukhopadhaya J (2001) et al. ${ }^{10}$ Suzuki $M$ et $\mathrm{al}^{11}$ found that exposure to environmental tobacco smoking was associated with hospital admission of children for pneumonia. Present study showed that no. of cases were more in females using cooking fuel other then LPG.

Comparable to study by Tielsch JM et al (2009).12 and Pandey MR et al. ${ }^{13}$ But indoor air pollution by biomass fuel was not significantly associated in current study. Tiewsoh $\mathrm{K}$ et al. ${ }^{14}$ in a hospital based study also found that majority i.e. $68 \%$ cases of ARI were from overcrowded families similar to current study. Overcrowding had clear association with morbidity but not with mortality in current study. Yousif TK et al. ${ }^{2}$

Conducted hospital based study and have similar frequency of hospital admission i.e, maximum in winter season like current study. The possible explaination for rise in cases during winter months could be due to longer survival of bacteria and viruses.ARI were more common with increase in the level of exposure to domestic smoke pollution.

CONCLUSION AND RECOMMENDATIONS: The present study identifies -family h/o smoking significantly associated with outcome of ARI Information on risk factors, along with feasibility and cost considerations, is essential for guiding preventive strategies against respiratory infections in children. Improvisation in housing pattern, ventilation should be advised within economical constraints.

The important intervention to reduce exposure to indoor air pollution is to promote widespread use of cleaner fuels, such as LPG and electricity.

Therefore, the efforts are needed to focus on providing improved cook stoves/smokeless chullas designed to reduce exposure to smoke by means of improved combustion and improved venting, and designing public health information campaigns to inform people about the health risks of exposure to indoor smoke.

Health education should be given to community about preventive measures such as need to avoid overcrowding and indoor smoke. Strengthening of ARI control through the mass media, training of doctors and medical workers, integration of Programme with Non-Governmental organization. Integrated approach is needed to prevent and control ARI.

\section{REFERENCES:}

1. Park K. Park's textbook of preventive and social medicine, 22nd ed. Banarsidas Bhanot Publishers, Jabalpur, India; 2013.

2. Yousif TK, Khaleq BA. Epidemiology of Acute Respiratory Tract Infections (ARI) among Children under Five Years Old Attending Tikirit General Teaching Hospital. The Middle East Journal of Family Medicine. 2006; 4(3):4-23.

3. Mitra NK A longitudinal study on ARI among rural underfives. Indian Journal of Community Medicne.2001; 26(1):811.

4. Wallace RB, Kohatsu N, Last JM, editors. Maxcy-RosenauLast Public Health and Preventive Medicine. $15^{\text {th }}$ edition. New York: McGraw-Hill: 2008.

5. Bharti B, Bharti S, Verma V.Severe Pneumonia in a Remote Hilly Area: Integrated Management of Childhood Illness. Indian Journal of Paediatrics. 2006; 73:33-7.

6. Baqui AH, Rahman MK, Zaman K, Arifeen S, Chowdhury HR, Begum N et al.A population-based study of hospital admission incidence rate and bacterial aetiology of acute lower respiratory infections in children aged less than five years in Bangladesh. J health Population nutrition 2007;25(2):179-88.

7. Savitha MR, Nandeeshwara SB, Pradeep Kumar MJ et al. Modifiable Risk factors for Acute lower Respiratory Infection. Indian Journal of Paediatrics. 2007;74:477-81.

8. Broor S, Pandey RM, Ghosh M, Maitrry RS, Lodha R,Singhal $\mathrm{T}$ et al. Risk factors for severe Acute lower Respiratory Tract infection in under five children. Indian Journal of paediatrics 2001;38(12):1361-68.

9. Sahu SK, Sathapathy DM, Sahu T, Tripathy RM,Das BC,Pradhan S.A study of acute respiratory infection cases admitted to a tertiary level health centre.Health and Population-Perspectives and Issues. 2002;25(4):186-95.

10. Mukhopadhaya J. Acute Respiratory infection among childrenin air force community. MIAFI.2001;57(4):309-11.

11. Suzuki M, Thiem VD, Yanai H, Matsubayashi T, Yoshida LM, Tho LH et al. Association of environmental tobacco smoking exposure with an increased risk of hospital admission for pneumonia in children under 5 years of age in Vietnam Thorax.2009;64:484-89.

12. Tielsch JM, Katz J,Thulasiraj RD,Coles CL,Sheeladevi S,Yanik EL et al.Exposure to indore biomass fuel and tobacco smoke and risk of adverse reproductive outcomes, mortality, respiratory morbidity and growth among newborns infants in South India. International Journal of epidemiology. 2009;38:1351-63.

13. Pandey MR, Neupane RP, Gautam A, Shrestha IB. Domestic Smoke Pollution and acute respiratory infections in a rural community of the hill region of Nepal. Environment International.1989;15:337-40

14. Tiewsoh K, Lodha R, Pandey RM, Broor S, Kalaivani M, Kabra SK. Factors determining the outcome of children hospitalized with severe pneumonia. BMC Paediatrics. 2009 9(15). 


\begin{tabular}{|c|c|c|c|c|c|c|c|c|}
\hline \multirow{3}{*}{\multicolumn{2}{|c|}{ Socio-demographic Factors }} & \multicolumn{6}{|c|}{ Number of cases } & \multirow{6}{*}{$\begin{array}{l}\text { P value } \\
\\
0.569\end{array}$} \\
\hline & & \multicolumn{2}{|c|}{ Cured } & \multicolumn{2}{|c|}{ Deaths } & \multicolumn{2}{|c|}{ Total } & \\
\hline & & No & $\%$ & No & $\%$ & No & $\%$ & \\
\hline \multirow{3}{*}{ 1. Age group } & $<1$ year & 173 & 92.51 & 14 & 7.49 & 187 & 100 & \\
\hline & 1-5year & 109 & 94.78 & 06 & 5.22 & 115 & 100 & \\
\hline & $\geq 5$ year & 48 & 96.00 & 02 & 4.00 & 50 & 100 & \\
\hline \multirow{2}{*}{ 2.Gender } & Male & 198 & 92.52 & 16 & 7.48 & 214 & 100 & \multirow{2}{*}{0.1835} \\
\hline & Female & 132 & 95.65 & 06 & 4.35 & 138 & 100 & \\
\hline \multirow{2}{*}{ 3.Residence } & Urban & 222 & 92.50 & 18 & 7.50 & 240 & 100 & \multirow{2}{*}{0.1562} \\
\hline & Rural & 108 & 96.42 & 04 & 3.58 & 102 & 100 & \\
\hline \multirow{4}{*}{ 4.Religion } & Hindu & 224 & 93.33 & 16 & 6.67 & 240 & 100 & \multirow{4}{*}{0.78} \\
\hline & Muslim & 89 & 94.68 & 05 & 5.32 & 94 & 100 & \\
\hline & Christian & 04 & 100 & 00 & 00 & 04 & 100 & \\
\hline & Buddhist & 13 & 92.85 & 01 & 7.15 & 14 & 100 & \\
\hline \multirow{3}{*}{ 5.Type of Family } & Nuclear & 125 & 93.28 & 09 & 6.72 & 134 & 100 & \multirow{3}{*}{0.8877} \\
\hline & Joint & 167 & 94.35 & 10 & 5.65 & 177 & 100 & \\
\hline & Three generation & 38 & 92.68 & 03 & 7.32 & 41 & 100 & \\
\hline \multirow{3}{*}{ 6.Socio-economic status } & Lower class & 211 & 91.7 & 19 & 8.3 & 230 & 100 & \multirow{3}{*}{0.1008} \\
\hline & Middle class & 118 & 97.5 & 03 & 2.5 & 121 & 100 & \\
\hline & Upper class & 01 & 100 & 00 & 0.00 & 01 & 100 & \\
\hline \multirow{2}{*}{ 7.Education of Mother } & Illiterate & 100 & 90.9 & 10 & 9.1 & 110 & 100 & \multirow{2}{*}{0.1327} \\
\hline & Literate & 220 & 90.9 & 22 & 9.1 & 242 & 100 & \\
\hline \multirow{3}{*}{ 8.Education of Father } & Illiterate & 74 & 90.2 & 08 & 9.8 & 82 & 100 & \multirow{2}{*}{0.1343} \\
\hline & Literate & 256 & 94.8 & 14 & 5.2 & 270 & 100 & \\
\hline & Total & 330 & 93.75 & 22 & 6.25 & 352 & 100 & \\
\hline
\end{tabular}

\begin{tabular}{|c|c|c|c|c|c|c|c|c|}
\hline \multirow{3}{*}{\multicolumn{2}{|c|}{ Environmental Factors }} & \multicolumn{6}{|c|}{ Number of Cases } & \multirow{3}{*}{$P$ value } \\
\hline & & \multicolumn{2}{|c|}{ Cured } & \multicolumn{2}{|c|}{ Deaths } & \multicolumn{2}{|c|}{ Total } & \\
\hline & & No & Test & No & $\%$ & No & $\%$ & \\
\hline \multirow{2}{*}{ 1.Family history of smoking } & Present & 184 & 55.76 & 17 & 77.27 & 201 & 57.10 & \multirow{2}{*}{0.048} \\
\hline & Absent & 146 & 44.24 & 05 & 22.73 & 151 & 42.90 & \\
\hline \multirow{2}{*}{ 2.Type of fuel } & Fuel other than LPG* & 299 & 90.61 & 21 & 95.45 & 320 & 90.91 & \multirow{2}{*}{0.444} \\
\hline & LPG & 31 & 9.39 & 01 & 4.55 & 32 & 9.09 & \\
\hline \multirow{2}{*}{ 3.0vercrowding } & Present & 275 & 83.83 & 19 & 86.36 & 294 & 83.52 & \multirow{2}{*}{0.711} \\
\hline & Absent & 55 & 16.67 & 03 & 13.64 & 58 & 16.48 & \\
\hline \multirow{3}{*}{ 4.Season } & Winter & 145 & 43.94 & 08 & 36.36 & 153 & 43.46 & \multirow{3}{*}{0.784} \\
\hline & Summer & 81 & 24.55 & 06 & 27.28 & 87 & 24.72 & \\
\hline & Monsoon & 104 & 31.51 & 08 & 36.36 & 112 & 31.82 & \\
\hline & Total & 330 & 100 & 22 & 100 & 352 & 100 & \\
\hline \multicolumn{9}{|c|}{$\begin{array}{c}\text { Table 2: Association of Environmental factors with } \\
\text { outcome of Acute Respiratory Infections }\end{array}$} \\
\hline
\end{tabular}

\begin{tabular}{|c|c|c|c|c|}
\hline \multirow{2}{*}{$\begin{array}{c}\text { Sl. } \\
\text { No }\end{array}$} & \multirow{2}{*}{ Variable } & \multirow{2}{*}{ Odds Ratio } & \multicolumn{2}{|c|}{$\mathbf{9 5 \%}$ C.I for odds Ratio } \\
\cline { 3 - 5 } & & Lower & Upper \\
\hline 1 & Socio-economic status & 3.572 & 1.036 & 12.32 \\
\hline 2 & Family History of smoking & 2.698 & 0.9724 & 7.485 \\
\hline 3 & Type of fuel & 2.177 & 0.2832 & 16.74 \\
\hline 4 & Education of Father & 1.977 & 0.7987 & 4.893 \\
\hline 5 & Education of Mother & 1.917 & 0.7771 & 4.581 \\
\hline 6 & Overcrowding & 1.267 & 0.3624 & 4.428 \\
\hline 7 & Seasonal variation & 0.729 & 0.2978 & 1.785 \\
\hline \multicolumn{6}{|r|}{ Table 3: Association of socio-demographic and environmental factors with outcome of ARI cases in } \\
decreasing order Univariate Analysis \\
\hline
\end{tabular}

